\title{
WHO collaborating centres in the Eastern Mediterranean Region: an agenda for action and improvement
}

Arash Rashidian ${ }^{1}$, Ahmed Mandil ${ }^{2}$, Samar ElFeky ${ }^{3}$ and Ahmed Al-Mandhari ${ }^{4}$

\begin{abstract}
${ }^{1}$ Director, Information, Evidence and Research, World Health Organization Regional Office for the Eastern Mediterranean, Cairo, Egypt. ${ }^{2}$ Coordinator, Research, Development and Innovation, World Health Organization Regional Office for the Eastern Mediterranean, Cairo, Egypt. ${ }^{3}$ Technical Officer, Research Promotion and Development, World Health Organization Regional Office for the Eastern Mediterranean, Cairo, Egypt. ${ }^{4}$ Regional Director, World Health Organization Regional Office for the Eastern Mediterranean, Cairo, Egypt.
\end{abstract}

Citation: Rashidian A; Mandil A; ElFeky S; Al-Mandhari A. WHO collaborating centres in the Eastern Mediterranean Region: an agenda for action and improvement. East Mediterr Health J. 2018;24(11):1035-1037. https://doi.org/10.26719/2018.24.11.1035

Copyright (c) World Health Organization (WHO) 2018. Some rights reserved. This work is available under the CC BY-NC-SA 3.0 IGO license (https:// creativecommons.org/licenses/by-nc-sa/3.o/igo).

The World Health Organization (WHO) is the key United Nations specialized agency dedicated to promoting population health and health outcomes. In order for the Organization to achieve its strategic objectives, WHO designates selected institutions as collaborating centres to assit with carrying out WHO core activities. The Eastern Mediterranean Region (EMR) currently hosts 45 collaborating centres (as of December 2018), which is only $5 \%$ of the $832 \mathrm{WHO}$ collaborating centres located worldwide (1), and yet EMR countries host about $10 \%$ of the global population. The reason for this discrepency could be a reflection of the limited public resources allocated to health research in the Region (2). However, it may also highlight the fact that resources and opportunities for establishing effective collaborating centres in the EMR still remain untapped.

There are country variations within the Region; for example, the Islamic Republic of Iran alone hosts 35\% (16) of collaborating centres, followed by Jordan, Morocco and Pakistan (each hosting four centres) (3). This clearly highlights that other EMR countries may have potential institutions and organizations that could provide further support for WHO's programme of work through the establishment of new collaborating centres, as well as expanding the work of existing centres. Moreover, WHO collaborating centres are ideally positioned to contribute to the development of institutional capacity in Member States and regions, and are a reflection of an international collaborative network for promoting population health equitably and effectively. Thus, collaborating centres can effectively support WHO in at least four of its six core functions at regional or global levels (4), namely:

1. Generation, translation and dissemination of valuable knowledge (e.g. research conduct and dissemination of its outcomes);

2. Production of research evidence and supporting the processes required in "setting norms and standards" (e.g. supporting guideline development and adaptation);

3. Development and evaluation of evidence for "evidence-based policy options" (e.g. developing policy briefs and guidelines for policy dialogue); and

4. Contribution to "monitoring the health situation and assessing health trends" (e.g. conducting surveys, burden of disease studies)

Nevertheless, WHO collaborating centres face important challenges in their functions from both the Organization and regional governments. Dr Ahmed Al-Mandhari, WHO Regional Director for the Eastern Mediterranean, has committed to expanding the number and scale-up functions of the collaborating centres in the Region, and address the following challenges appropriately (5), namely technical capacity and planning challenges; financial and resource challenges; and administrative and communication challenges.

Technical and planning challenges stem from the capacity ability of collaborating centres in response to WHO needs and population health priorities in the Region, as well as globally. These challenges often start before the designation of "collaborating centre" by WHO, since the majority of such institutions are already established in response to existing national demands. Therefore, such centres that have already excelled at the national level in response to country needs may not necessarily be equally prepared to expand their technical support for the wider needs of WHO. Hence, the focus is usually on what the centre can already offer the Organization, rather than adapting to the priority needs of WHO. Moreover, lack of attention to the proper planning of collaborative work following designation by WHO may result in missed opportunities for effective collaborative actions.

Financial and human resource challenges are also among the key barriers. By definition, WHO collaborating centres use their capacity and resources to support WHO's programme of work. While they benefit from close work with the Organization, the centres also require key infrastructure for productive action. As many health research institutions in the Region lack long-term funding streams from public resources, they may not be well-placed to respond to WHO's needs. Also, when funded by national public resources, such centres may find it politically difficult to justify those actions that go beyond national remits. To help mitigate this, WHO should provide further recognition for the collaborating centres' wider work and perceived impact in order to support national institutions for regional or global action. 
While administrative and communication challenges are an extrapolation of what has been described, there are some particular aspects of working with the centres that require further attention. In fact, the processes of designation, continuation (re-designation), or discontinuation (termination) of a WHO collaborating centre follow a set of relatively strict rules and regulations (6). The regulations are based on the decisions of WHO governing bodies, and are formulated to ensure that such high-level decisions are not abused or misused in any form. This means that the setting up of a WHO collaborating centre work plan, based on specific terms of reference and related activities, not only requires attention to the technical and resource-related aspects, but also recognition of what is permissible as part of its agenda of work. However, the imposition of such regulations may also result in important time lags in the implementation of the agenda, as well as in submission or ratification of a centre's reports.

In support of the Eastern Mediterranean Vision for 2023 (7) and WHO's 13th General Programme of Work (GPW13) (8), the WHO Eastern Mediterranean Regional Office (WHO/EMRO) is following a set of strategic actions to enhance the number and functions of WHO collaborating centres in the Region. This follows the ambitious agenda of furthering collaborative work for health by 2023 via tapping into the existing academic and policy development and implementation capacity in the Region. In addition, it also offers recognition of the existing quality work in the Region and enhances regional and national institutional capacity for improving population health. The regular conduct of WHO collaborative centre meetings, as well as implementing innovative approaches to promote excellence, are important directions for action (9).
Still, it is also important that WHO acts proactively in the identification of priority areas of action for the Organization, as well as identifying those potential institutions of excellence that can act as collaborating centres. As an example of the former, we are developing a list of priority areas for collaboration that can be taken up by existing collaborating centres or those that may wish to be designated as such. These priority areas are focused on the needs of the Region and include health and healthcare in emergency settings (10), neglected tropical diseases and priority communicable diseases(10), noncommunicable diseases and risk factors that have received less attention (10), maternal and child health and vulnerable groups (10), health system development (10), as well as health information and evidence informed decision-making (11). In addition, for the first time we are also planning pro-active events in a number of Member States in which we invite high calibre academic and research institutions in the country to raise their understanding of WHO collaborating centres. Three such events are already scheduled for 2019.

Looking forward, we expect to see more resources from those countries with higher research and analytical capabilities made available in support of WHO activities. However, this does not preempt the need for expansion of WHO collaborating centres in the Region. All these factors are the focus of an upcoming meeting of WHO collaborating centres, scheduled to be held in Muscat, Oman, during January 2019. The deliberations and outcomes of the meeting will be used to finalize a regional plan of action for improvement in light of WHO GPW13 and EMR Vision 2023.

\section{References}

1. World Health Organization. WHO collaborating centres global database. Geneva: World Health Organization; 2018 (http://apps. who.int/whocc/List.aspx?cc_region=EMRO\&).

2. Røttingen JA, Regmi S, Eide M, Young AJ, Viergever RF, Årdal C et al. Mapping of available health research and development data: what's there, what's missing, and what role is there for a global observatory? Lancet 2013; 382: 1286-307. https://doi.org/10.1016/ So140-6736(13)61046-6 PMID: 23697824

3. Sharifi H, Akbarein H, Akhondzadeh S, Amirkhani M, Asadi-Lari M, Ayatollahi Mousavi SA, et al. Establishment of the National Network of WHO Collaborating Centres in Iran to Contribute to the National Public Health Needs. Arch Iran Med. 2015; 18(8):558-9 https://doi.org/015188/AIM.0017 PMID: 26265527

4. Singh PK. Collaborating centres: Rediscovering an extended arm of World Health Organization. Indian J Med Res. 2018; 147(1):1113. https://doi.org/10.4103/ijmr.IJMR_118_18 PMID: 29749355

5. Mandil A, ElFeky S, Rashidian A. Assessment of World Health Organization collaborating centres in the Eastern Mediterranean Region. East Mediterr Health J. 2017; 23(10):711-714. https://doi.org/10.26719/2018.23.10.711.

6. World Health Organization. Guide for WHO collaborating centres. Geneva: World Health Organization; 2018 (http://www.who. int/collaboratingcentres/Guide_for_WHO_collaborating_centres_2018FINAL.pdf).

7. World Health Organization Regional Office for the Eastern Mediterranean (WHO/EMRO). Vision 2023 - Eastern Mediterranean Region. Cairo: WHO/EMRO; 2017 (http://www.emro.who.int/about-who/vision2023/vision-2023.html).

8. Mahjour J, Mirza Z, Rashidian A, Atta H, Hajjeh R, Thieren M, et al. "Promote health, keep the world safe, serve the vulnerable" in the Eastern Mediterranean Region. East Mediterr Health J. 2018; 24(4):323-324. https://doi.org/10.26719/2018.24.4.323 
9. World Health Organization Regional Office for the Eastern Mediterranean (WHO/EMRO). Third meeting of the WHO collaborating centres in the Eastern Mediterranean Region, Meeting report. Cairo: WHO/EMRO; 2015 (http://applications.emro.who.int/ docs/IC_Meet_Rep_2015_16727_EN.pdf?ua=1).

10. Fikri M. Roadmap 2017-2021: Stronger organization and better response to the needs of Member States in the Eastern Mediterranean Region. East Mediterr Health J. 2017; 23(5): 327-328. https://doi.org/10.26719/2017.23.5.327

11. Rashidian A, Mandil A, Mahjour J. Improving evidence informed policy-making for health in the Eastern Mediterranean Region. East Mediterr Health J. 2018; 23(12): 793-794. https://doi.org/10.26719/2018.23.12.793. 